\title{
NORMS IN DELIBERATION: THE ROLE OF THE PRINCIPLES OF JUSTICE AND UNIVERSALIZATION IN PRACTICAL DISCOURSES ON THE JUSTICE OF NORMS
}

\begin{abstract}
Discursive theories of justice have been questioned for putting forward high-level principles that should nevertheless play a role in practical discourses in which the justice of a claim is at stake. Here, I will critically examine and systematize the main tenets in Rawls's and Habermas's discursive theories, and will suggest that the principles of justice (Rawls) and universalization (Habermas) can and play the role of mandates of optimalization in real deliberations on justice.

Keywords: discursive theories, principles of justice, principle of universalization, deliberation, Rawls, Habermas.
\end{abstract}

\section{Introduction}

Constructivism in moral and political philosophy is the view that (i) there are correct normative claims about what one ought to do and (ii) they depend on how rational agents would reason in an idealized deliberative situation (Rawls 1999, 1980, 2001; Habermas 1990, 1996; Alexy $1978,1988,1993)$. To substantiate this thesis, these theories are also procedural and discursive, claiming that the correctness of a norm depends upon whether the norm can be the result of a certain discursive procedure, conceived as an idealized deliberation process subject to certain conditions. Within this common framework, the answer to the question whether or not a norm $\mathrm{N}$ is correct is given in virtue of a general principle that can be stated as follows (cf. Alexy 1988: 44),

Discursive Thesis: A norm $\mathrm{N}$ is correct, if and only if it can be the result of the discursive procedure $\mathrm{P}$.

In order to sustain this thesis in particular, discursive theories of the correctness of normative claims have to face two main tasks. The first one 


\section{Cristina Corredor}

is to specify the procedure that should fulfil this function; the second task is to answer the question of how the result of the procedure is connected to the correctness of its outcome. In this paper I am going to mainly focus my attention on the first task, concerned with the discursive procedure in virtue of which a normative claim can be declared to be a correct norm. I will, nevertheless, briefly address the second one, related to the internal connections between a discursive procedure and a correct outcome.

I will mainly take into account the moral and political philosophy of John Rawls and Jürgen Habermas, and the discursive theory of Law due to Robert Alexy. I consider these authors to be highly prominent representatives of the views to be examined here. According to these views, while metaethical constructivism is concerned with all normative claims, political constructivism is only concerned with the principles of justice of the basic institutions of society and with the procedure allowing a normative claim to be legitimated as a just norm ${ }^{1}$. In what follows, I am going to focus on procedural theories of justice, taking into account this conceptual scope.

\section{Main tenets in discursive theories of justice}

\subsection{Discursive procedure}

Rawls's principles of justice as fairness articulate the central liberal ideas that cooperation should be fair to all citizens regarded as free and as equals. He suggests that the question, "What are fair terms of social cooperation for free and equal citizens?", can and should be transformed into the question "What terms of cooperation would free and equal citizens agree to under fair conditions?" This move towards agreement makes of Rawls's theory of justice a procedural, discursive one, thus having to face the above mentioned first task.

As is well known, in order to answer this challenge, he envisages an original position in which the participants do not know the personal features of any of the citizens in this society (race, ethnicity, gender, age, wealth, natural endowments, etc.), nor its political system. From their deliberation, two normative principles of justice are expected to be drawn:

Principle of equal basic liberties: Each person has the same indefeasible claim to a fully adequate scheme of equal basic liberties, which scheme is compatible with the same scheme of liberties for all. 
Norms in Deliberation: The Role of the Principles of Justice and...

Principles of equality of opportunity and of difference: Social and economic inequalities are to satisfy two conditions:

a. They are to be attached to offices and positions open to all under conditions of fair equality of opportunity;

b. They are to be to the greatest benefit of the least-advantaged members of society.

(Rawls 2001: 42-43)

Rawls declares that the original position embodies all of the relevant conceptions of person and society, and principles of practical reasoning for making judgments about justice. Once the principles of justice are derived, the first task is complied with by virtue of a public use of reason aiming at establishing which norms are just. In this process, the participants are guided by the two principles of justice and assume the mutual recognition of each other as free and equal moral persons. ${ }^{2}$ Moreover, Rawls assumes that the participants in public discourses, qua moral persons, are rational and reasonable. Reasonable citizens have the capacity to abide by fair terms of cooperation, notwithstanding their own interests. Rational citizens have the capacity to pursue and revise their own view of what is valuable in human life.

For his part, Habermas has put forward an idealized notion of practical discourse which embeds a notion of validity applicable to all practical claims. He does so by means of a discursive principle:

Discourse principle (D): Just those action norms are valid to which all possibly affected persons could agree as participants in rational discourses. (Habermas 1996: 107)

Principle D applies not only to moral rightness and ethical authenticity, but also to the justification of other pragmatic claims (e.g. about meansend, legality, prudence, etc.) The discourse principle is only intended to explain the point of view from which norms of action can be impartially justified. In order to justify this principle, Habermas writes, "I assume that the principle itself reflects those symmetrical relations of recognition built into communicatively structured forms of life in general" (1996: 109). With this statement, however, he goes beyond the limits of the pragmatics of argumentation as such, to embrace a strong thesis that concerns the pragmatics of speech and certain highly idealized presuppositions that, according to this view, underlie speech. According to this thesis ${ }^{3}$, with their speech acts, speakers raise certain validity claims concerning the correctness (truth, rightness, authenticity) of their speech. Moreover, whenever they engage in 


\section{Cristina Corredor}

a joint argumentative discourse to revise problematized validity claims, they cannot but presuppose that certain ideal conditions (of symmetry among participants, freedom from coercion, etc.) are sufficiently in force.

Furthermore, Habermas contends that (D) can be further specified within certain domains of discourse. In particular, he takes it that a moral principle results when one specifies $\mathrm{D}$ for those norms that can be justified if, and only if, equal consideration is given to the interest of all those who are possibly involved. This moral principle takes the following form:

Principle of Universalization (U): For a norm to be valid, the consequences and side effects that its general observance can be expected to have for the satisfaction of the particular interests of each person affected must be such that all affected can accept them freely. (Habermas 1990: 120)

Therefore, an answer to the first task is accomplished by assuming a deliberative process in which the participants are guided by principle U. Yet one may wonder how this guidance has to take place. Habermas says that $\mathrm{U}$ is an operationalization of $\mathrm{D}$ in the realm of moral discourse, therefore it can be seen as a rule of argumentation. He writes, "For the justification of moral norms, the discourse principle takes the form of a universalization principle. To this extent, the moral principle functions as a rule of argumentation." (1990: 109) Habermas's critics have remarked that U does not have the character of other usual argumentation rules, since it is not formal and schematic. It can be said to be a substantive rule, in that it has a certain ethical content. U refers to a particular group, namely, the group of all affected persons, and requires from each of them that they should take into account the free response of all the others. Within a deliberation procedure as the one here envisaged, this amounts to a requirement from all the participants that they seek an agreement based on reasons that all can recognize and accept.

Therefore, concerning the first task as described above, the procedure that should allow the participants to seek agreement on the norms under discussion is to be (and only can be) an argumentative procedure subjected to certain requirements. This is developed in more detail within Habermas's philosophical framework by his explicit endorsement of Alexy's theory of argumentation. Practical discourse is seen as a procedure to prove and justify normative and value claims by means of arguments. Moreover, this theory subsumes the thesis that the requirements of rational practical discourses can be entirely formulated by rules. These rules include, among other requirements: 
- Logical-semantic rules of non-contradiction, clearness of language, empirical truth and sincerity

- Rules with a moral content: rules which express the idea of universality, i.e., they give everybody the right to participate in the discourse and grant everybody equal consideration in the discourse, including the right of everybody to put forward and criticize every claim

- Pragmatic-empirical rules: rules which concern the consideration of consequences, the weighing of reasons and the analysis of the genesis of normative convictions (Alexy 1988: 46; see also his 1978: $234 \mathrm{ff}$.)

Alexy explicitly acknowledges that "a number of the rules are only approximatively fulfilable" (1988: 47-48). It is worth noticing that this remark seems somewhat in tension with the thesis he has defended in another place, in relation to legal argumentation; according to this thesis, principles must be distinguished from rules in that the former are mandates of optimalization, whereas the latter are definite mandates (cf. Alexy 1993). The distinction between rules that are mandates of optimalization, and definite mandates, is going to be particularly relevant in the subsequent discussion (see below, section 3.4)

At this point, by accepting that there are rules of the discourse which are only approximately fulfilable, Alexy draws the conclusion that discourse theory does not guarantee a definite decision in each case. This amounts to acknowledging that there may not be just one right or correct answer to each practical question, a result that impinges on the second task, concerned with the link between discursive procedure and correctness. Still, Alexy seems to consider that, from all the set of rules, two of them have an essential role and constitute the normative basis of discourse (cf. Alexy 1993: 40). The discourse rules must guarantee to all, (i) The right to take part in the discourse, and (ii) The right to put forward and criticize every claim. In order to justify them, Alexy writes, "The proponents of a discourse theory of norms have contended that these rules that express non-trivial demands for universalizability are capable of a transcendental-pragmatic justification by way of a presupposition-analysis." (Alexy 1978: 230 ff.; cf. Habermas 1990) This commentary points to the question of whether a discursive procedure as the one here envisaged can warrant a correct outcome, in the sense of yielding just norms.

\subsection{Correctness of the outcome in discursive procedures}

With respect to the second task, the question of how the result of the procedure is connected to the correctness of its outcome, Rawls writes, 


\section{Cristina Corredor}

Whether certain facts are to be recognized as reasons of right and justice, or how much they are to count, can be ascertained only from within the constructive procedure, that is, from the undertakings of rational agents of construction when suitably represented as free and equal moral persons. (Rawls 1980: 519; my italics)

Thus, a normative claim can be recognized as a just norm only if it can be ascertained as the outcome of the public use of reason. We may wonder whether the constructive procedure is to be seen as a constitutive condition of justice, in the strong sense of being the only means to establish just norms. Yet the locution 'only from' suggests that Rawls conceives of the deliberative procedure as a necessary condition. Notice that, in the above quoted passage, he refers to the possibility of ascertaining a fact as a reason of right and justice. Rawls is pointing out what he takes to be the only feasible means of so doing. To that extent, his claim concerns human moral knowledge and argumentativeness. As such, it is not a constitutive thesis in the strongest sense.

Rawls holds a pluralistic view of liberal conceptions of justice. According to this view, the fundamental ideas that the public culture of a democratic society has to acknowledge (the equality and freedom of citizens, and a view of society as a fair system of cooperation), can find expression in many different reasonable interpretations of the notions of freedom, equality, and fairness. Yet he contends that all liberal political conceptions of justice should share certain formal, basic features, related to the ascription, prioritization, and guarantee of individual rights and liberties to all citizens. To ground this idea, Rawls's pluralistic view has to be supplemented with his concept of the original position. Under the conditions of the original position, an overlapping consensus focused on justice as fairness is objectively correct, in the sense that its outcome gives reasons to citizens to act, regardless of their actual motivations or particular points of view (cf. Rawls 1999: 442-454). We may take it that, to the extent that actual public debates are faithful to the principles of justice as fairness so obtained, or are sufficiently close to them, their outcome can be considered reasonable and objectively correct. To that extent, there is no other standard or criterion, external to the debate, to assess the justice of a norm.

This conclusion might be in contrast to Habermas's views. In identifying morality with justice, he declares the moral standpoint to be that "of equal respect for each person and equal consideration for the interests of all" (1996: 99). This statement suggests a substantive criterion of justice, namely, the concept of an interest which is common to all persons affected. 
This concept is made explicit when Habermas writes,

True impartiality pertains only to that standpoint from which one can generalize precisely those norms that can count on universal assent because they perceptibly embody an interest common to all affected. (1990: 65)

At the same time, however, Habermas characterizes the moral point of view as one that constraints all affected to adopt the perspectives of all others, in the balancing of interests (ibid.) As Lafont (2004) has critically noticed, the idea of a common interest of all affected seems to be susceptible of two different readings. In a weakened reading, it would be identical to the outcome of a practical discourse, whenever the interests of all affected have been taken into consideration on equal terms. This constraint would play a similar role, therefore, to that of the original position in Rawls's conception of justice. Yet a stronger reading would commit Habermas to the presupposition that there are, as a matter of fact, common universal interests, whose ascertainment would be the object and goal of moral argumentation. In answering this criticism, Habermas has stressed that an interest of this kind is not something given, thus approaching his own position to that of Rawls. But Lafont insightfully remarks that, as a result, justice and legitimacy turn out to be indistinguishable.

In tune with Rawls's and Habermas's views (in the weakened reading seen above), Alexy says that, at least in practical questions which are essentially concerned with the interpretation and reconciliation of interests (therefore, with questions of justice), there are no good reasons as such, since "[w] hat actually is a good reason can only be revealed in the process of discursive investigation" (1988: 56-57) This tenet reveals that discourse theory is underlain by another presupposition:

Discourse theory presupposes that the participants of discourse, that is, human beings, such as they actually exist, are generally able to distinguish between good and bad reasons for substantial propositions. (ibid.)

This consideration allows us to conclude that, together with certain formal principles (Rawls's principles of justice, Habermas's principle of universalization), there are two general ideas underlying the discursive theory of justice. These ideas are, firstly, the requirement of mutual recognition of the participants as free and equal persons, and secondly, the presupposition that the participants are argumentatively competent and able to distinguish between good and bad reasons for substantial propositions. My aim in what follows is to pay closer attention to the role that those high-level claims can and do play in our practical deliberation on just norms. 


\section{Practical discourses and the justice of norms}

\subsection{Main ideas and principles in discursive justice}

The preceding ideas may be summarized as follows. Firstly, in what can be seen as a common tenet, discursive theories of justice incorporate some main ideas in the background, which are seen as basic guiding ideas conceptually required by the notion of justice as fairness (Rawls) or as unavoidable presuppositions of justice in any moral discourse (Habermas, Alexy). These ideas include: firstly, a consideration of the others as free and equal moral persons (Rawls); or, a mutual recognition of others as free and equal (Habermas, Alexy); and secondly, a consideration of others as capable of acting both reasonably and rationally (Rawls), or a consideration of the others as able to distinguish between good and bad reasons for substantial propositions.

A second common tenet in these positions is their thesis that in order for a normative claim to be just, it must be susceptible of being ascertained in an idealized deliberative situation, namely, the original position (Rawls) or an ideal practical discourse (Alexy, Habermas). Both situations embody strong idealized conditions. In the original position, the participants are able to reason and act notwithstanding their own interests. In practical discourses, all those affected by the norm at issue have a right to participate and are allowed to put forward and criticize every claim. In both cases, these conditions aim to guarantee an impartial standpoint. Moreover, in Habermas's model the idealized conditions of practical discourses require an equal consideration of the interests of every one. Although impartiality is equated to reasonableness in Rawls's model, the original position does not require the same strong condition, but assumes instead that no particular interest needs to play a role. This idea may be seen, therefore, as a significant point of demarcation between the two.

A third common tenet is the assumption that, once the main principles of justice have gained credibility (Rawls) or the universalization principle is in force as an operative rule (Habermas), other normative, although less certain, claims can be subject to deliberation under the guidance of these principles. However, it is not evident whether and how these elements can and should be incorporated within the framework of practical argumentation. Practical discourses of application would be possible, we may interpret, either taking an explicit point of departure in some of the principles and ideas stated above, or using them as critical standpoints to question and assess proposals and claims. 
Notwithstanding this, discursive theories of justice have been confronted with the objection that our real practices of argumentation do not seem to be subject to such idealized and high-level principles and ideas, not even when people deliberate about normative claims related to their ideas of justice and moral rightness. According to this objection, it is possible to ask whether a certain normative claim should be adopted and to give arguments for or against it, without having to presuppose implausible ideal conditions such as the requirements of the original position and of the ideal practical discourse. Moral particularism, for example, dismisses the need to take into account general principles, when a person or a group of people deliberate on how to act. Moral deliberation, according to this view, can proceed by trying to work out what matters in the particular situation, in ways that may involve a consideration of other situations sufficiently similar to the present one. As Dancy has put it, "the possibility of moral thought and judgement does not depend on the provision of a suitable supply of moral principles" (Dancy 2004: 73). A more nuanced point of view could concede that, even if there are no principles of justice that would provide us with ultimate reasons, "we would nevertheless require principles of justice to regulate policy and institutions", these principles being of a kind as reasonably clear and precise as possible, to allow for a public assessment of their application (Mason 2009: 193). Notice, however, that such principles could not be seen as universally valid and objective, but relative to a particular legal system, a cultural and social framework, etc. Furthermore, these regulating principles should be substantive and not formal, given the requirements of clarity and precision for their application and assessment.

It seems to me that this objection can be dealt with at two levels. One level concerns the justification that a discourse theory can offer for its strong tenets. This is something that the proponents of these views have worked out in other places, and I cannot discuss here. A second level is related to a critical analysis and clarification of the operationalization of these ideas and principles within practical discourse. To approach this second level of analysis, my suggestion is to take as a methodological point of departure Toulmin's (1958) model of argument, trying to clarify whether and how the three different elements identified above, namely, some general guiding ideas of equality and respect, the strong requirements of an idealized deliberative situation, and the high-level principles of justice and universalization can be integrated within it.

In Toulmin's model, argumentation is conceived as a communicative activity where a claim is put forward together with the reasons, data, evidence, etc. that are adduced in support of it. These two acts of adduc- 


\section{Cristina Corredor}

ing (a reason) and concluding (a target-claim) are internally connected by means of a further act of the speaker, which amounts to asserting (possibly implicitly) the inferential claim that if the reasons are correct, then the claim also is correct ${ }^{4}$. This inferential claim is represented by means of a warrant which, as Toulmin claimed, may be, and usually is, left tacit or implicit, although in the course of an argumentative dialogue can become explicitly questioned. When this happens, there seems to be a shift in the argumentative dialogue that makes of (the utterance explicitating) the warrant a claim subject to further justification. It becomes also susceptible of support by means of another claim, which is then in its turn conceptualized as a backing.

\subsection{General ideas of freedom and equality of persons and argumentative competency}

It seems to me that the general ideas concerning the recognition of others (as free and equal persons, and as capable of acting reasonably and rationally, or as capable of distinguishing good and bad reasons for substantive claims) should be taken to be part of the common background on which deliberation as a communicative practice can take place. We may say that the recognition of the others as equal and free persons and as able to participate in deliberations must be part of what, borrowing this term from Gauker (1997), can be conceptualized as the common cooperative domain of practical discourse. Gauker's notion is based on reasonable mutual expectations of both speaker and hearer with respect to the meaning of a statement at issue. In our present framework, these mutual assumptions must be referred to the normative statuses that the participants in a practical discourse have to recognize in each other (in terms of rights and mutual obligations).

My claim does not entail that real practical deliberations always guarantee that these conditions be satisfied; but I suggest that explicitly denying them (denying e.g. that a participant has an equal right to put forward a claim or to express her interests) amounts to a practical inconsistency. The participant who acts in this way, denying others the discursive rights of making a claim or expressing their interests, is nevertheless presenting his or her own arguments and criticisms, thus expecting from others respect and consideration for them. This kind of inconsistency contradicts the basic requirements of any deliberative discourse. Moreover, as it stands, the assumption that the participants should recognize each other as free and equal, and that they should consider each other rational and reasonable, or argumentatively competent, makes possible a critical examination 
and negative assessment of those discourses in which these conditions have been openly unmet. To that extent, these high-level, normative ideas can be operationalized as reasons available on the argumentative field of practical discourses. These general ideas (of others as free and equal, and as argumentatively competent) can also play the role of backings for the inferential claims that ground particular arguments for or against a normative claim.

\subsection{The idealized deliberative situation}

A similar role can be assigned to the strong requirements presupposed in the idealized deliberative situations of the original position (Rawls) and practical discourses (Alexy, Habermas). As suggested above, these requirements are intended to guarantee an impartial point of view and, in Habermas's model, equal consideration to the interests of all. Even if many (perhaps most) real deliberative processes do not comply with them, these presuppositions can and do play a decisive role in the critical assessment of the outcome of such processes.

For instance, whenever the right to put forward a proposal or to criticize a claim is denied to some participant, unless there are good reasons that justify it, not only is the outcome doomed to lack legitimacy (in the political sense of public democratic recognition), but its very correctness and rationality are at stake. Similarly, if a decision is taken that has a negative effect on the interests of some person and this person's interests have not been duly taken into account, the justice of the decision is at stake.

Considering all this, the above-mentioned assumptions can be taken to also be part of the common cooperative domain and are available both as reasons and as backings for the inferential claims (represented as warrants) of the arguments in play.

\subsection{The principles of justice and universalization}

Rawls's principles of justice and Habermas's principle of universalization embody two different conceptions of justice, namely, justice as fairness and justice as the outcome of an equal consideration of the interests of all. Notwithstanding this difference, and from the point of view of the role that these principles play within the framework of a discourse theory of justice, my suggestion is that their roles are analogous in practical discourses. In both cases, the principles are invoked as norms of practical argumentation whenever the justice of a claim is at stake. In what follows, I will consider Rawls's principles of justice and Habermas's principle of universalization as being on a par in this respect. 


\section{Cristina Corredor}

Concerning their role in practical discourses, as we have already seen, they may act as a guide in the deliberation on other, less certain normative claims. The precise character of this guidance is nevertheless insufficiently clear. A first step towards this determination is immediate. These principles cannot be seen as inferential claims, authorizing the step from reasons to conclusion. For one thing, inferential claims are hypothetical claims; in contrast, the principles of justice and universalization are definite, in the sense that they define the very concept of justice. In a strong reading, the principles of justice and universalization state unconditional duties for the participants in public deliberations on the justice of norms.

This remark may seem to be at odds with Habermas's claim that the universalization principle is a rule of practical argumentation (quoted above). Yet I think that U's character as a rule is also in need of clarification. Habermas seems to think of the rules of discourse as general instructions on how to act in deliberative processes aiming at just norms. Also, discursive rules seem to play the role of inferential claims of a very abstract and general kind, so that the participants are encouraged to examine a particular claim at stake under the light of whether it is a claim that answers to the antecedent condition in U. To that extent, U seems to work as hypothetical rules do. But the universalization principle establishes very strong and high-level requirements, of a kind that (as critics have insisted) is very difficult to see fully complied with in real deliberations.

We have already observed that the fulfilment of certain rules can be, nevertheless, a matter of approximation. In this sense, the concept of rule can be taken to embrace both definite obligations and obligations that concern a mandate of optimalization ${ }^{5}$. Rules stating a mandate of optimalization are better conceptualized, it seems to me, as principles. Whereas there are rules that state definitive obligations, Habermas's universalization principle, as well as Rawls's principles of justice, are mandates to optimize. They guide in the search for this optimality and provide criteria of assessment for the outcome of deliberative processes, whenever the justice of a norm is at issue.

If this is correct, then the role of the principles of justice and universalization in practical argumentation cannot be that of reasons (premises). To see why this is so, we can notice that these principles are too high-level norms. In contrast, reasons in practical argumentation are usually of a different kind. For instance, in order to argue for the equity of a law increasing the minimum wage, a participant could invoke the idea of a dignified life, together with concrete references to e.g. the cost of living and the rise in inflation; it is nevertheless much less plausible that she would make appeal 
to the way in which the proposed minimum wage satisfies the principle of difference or universalizes what is equally in the interest of all. Yet those principles can play an important role, so I think, once the law has been passed. Then, it is the process of approval itself, qua practical discourse, what may be subject to critical scrutiny and become negatively assessed, if it is shown to have contravened the normative requirements embodied by these principles.

To correctly assess the character of the principles and the function they can play in practical argumentation, notice again that once they are in force, their force is categorical, even in those cases in which they act as mandates of optimalization. To that extent, they can be taken to play a certain constitutive role in practical deliberations, whenever these are concerned with the justice of norms. Yet the claim that these principles are constitutive must be further clarified. It can raise the immediate objection that mandates of optimalization should be seen as regulative rules and, to that extent, they cannot play at the same time a constitutive role. In order to answer to this objection, I suggest consideration of the distinction between two senses in which a rule can be said to be constitutive. The distinction, recently proposed by Sbisà $(2017)^{6}$, is originally applied to the force of speech acts and their illocutionary role, and depends itself on a distinction between the rules that are determinative of the correct performance of a speech act (so that non-compliance with them results in the act being null or void), and the rules that can make the act unhappy or defective, but do not amount to a void or null act.

A similar distinction can be applied in the case of the operationalization of the principles of justice and universalization. If the principles are constitutive of what justice is, i.e. if they introduce the very notion of justice by defining it in a definite sense, then the lack of compliance with them can only result in an unjust norm. In this light, the principles should be taken to be categorical, since without them the very notion of a just norm could not be made sense of. This assertion is not inconsistent with acknowledging that the principles can play, in practice, an optimalization role both in the deliberative process aiming at a just norm, and in the evaluative process of critically assessing the justice of a particular normative claim. In the latter case, the principles of justice and universalization provide criteria for critical assessment, in the former, they are guiding mandates of optimalization.

This amounts to distinguishing two levels on which the normative principles of justice and universalization can and should play a role. On the level of real deliberations on the justice of particular norms, my suggestion is 


\section{Cristina Corredor}

to see these principles as mandates of optimalization. They allow the participants to agree in the joint adoption of a normative claim as a just norm, even if provisionally, whenever the principles have been sufficiently taken into consideration and in the absence of a defeating argument. On this role, the principles can be introduced e.g. as main backings giving support to other inferential claims, or as conditions of rebuttal.

A more controversial tenet is the statement that the principles of justice and universalization are categorical and, to that extent, they should be seen as definite mandates for the very notion of a just norm. My aim is not to argue for this tenet here. My suggestion is that, whether or not one assumes this strong standpoint, it is possible to see the operationalization of the principles in terms of mandates of optimalization. It seems to me also possible to endorse the view that the principles are categorical and, at the level of their operationalization, consider that they play an optimalization role in tune with other mandates.

\section{Other relevant normative approaches to practical argumentation}

As is well known, Pragma-dialectics has put forward a concept of argumentation which is both normative and pragmatic. According to this theoretical view, argumentation is a verbal activity aimed at convincing a reasonable critic of the acceptability of a standpoint, by means of putting forward speech act complexes oriented at justifying (or refuting) the standpoint (cf. van Eemeren and Grootendorst 1982: 18; id. 2004: 10, 132). Argumentation is regarded as part of a procedure for resolving a difference of opinion on the acceptability of the standpoint at issue, and this by means of a critical discussion. This definition has a descriptive and a normative aspect. Descriptively, argumentation is seen as a speech act complex with similar properties to other speech acts. The reference to a reasonable critic adds a critical, normative dimension. It is worth paying closer attention to the notion of normativity thus advanced, since it can allow for a comparison with Habermas's and Rawls's views.

The pragma-dialectical analysis of the speech act complex of argumentation leads to the conclusion that there are 'first-order' conditions for conducting a critical discussion, and from these the theory draws a set of ten procedural rules. One may wonder whether these rules, inasmuch as they are in force in the practice of argumentation, are determining the notion of reasonableness in play and thus the normative dimension of argumenta- 
tion. A positive answer would entail that being reasonable should be taken to be equivalent to complying with the procedural rules of a critical discussion. But Pragma-dialectics seems to endorse a different approach. The procedural rules are themselves justified because of their specific contribution to the process of resolving a difference of opinion. They write, "These rules are to be considered as the rules that are to be followed in order to play the game effectively, and they are to be judged for their capacity to serve this purpose well - their problem-validity" (van Eemeren and Grootendorst 2004: 187). From a theoretical stance, it is their effectiveness at solving the difference of opinion what explains and justifies the introduction of the procedural rules of a critical discussion. Complementarily, in order for the rules to be in force, they have to be accepted intersubjectively by the potential discussants. In this way, the procedural rules acquire conventional validity as well. As the authors explicitly recognize, "argumentation theorists cannot go much further than to propose the rules and defend their acceptability" (ibid.)

The instrumental character of the procedural rules for a critical discussion in the Pragma-dialectics suggests that these rules are on a par with the rules stated in Alexy's theory of argumentation, as endorsed by Habermas, and also with Rawls's conceptions of rationality and reasonableness. Nevertheless, notice that the pragma-dialectical rules are conceptually subordinated to the ultimate goal of solving a difference of opinion. This subordinated character contrasts with Alexy's discursive thesis, according to which, as we have seen, a norm is correct if, and only if, it can be the result of certain discursive procedure. A constitutive reading of this thesis would be at pains with the pragma-dialectical approach, and this for the following reason. Notice that whenever the justice of a norm is under discussion, the pragma-dialectical rules are to be seen as instrumental in solving the differences of opinion that affect the norm, without the discussants' respect to the rules warranting that a final agreement entails the correctness of the norm. On the constitutive reading of the discursive thesis, it is the respect to the rules what warrants that the finally agreed norm is a correct norm.

Yet my suggestion has been that there can be a reading of the thesis that sees the compliance with the procedural rules of argumentation as a mandate of optimalization. Even from this perspective, Alexy's rules would retain a regulative character that is not instrumental in the pragmadialectical sense. Whenever the participants guide themselves by these rules, they will be acting in a way that allows them to be closer to a correct norm. Yet their willingness to pay respect to the procedural rules cannot 


\section{Cristina Corredor}

be seen as answering to an attempt to solve their difference of opinion, but to their shared goal of determining which norm is, in their situation, the correct one. This substantive concern is not part of the Pragma-dialectics framework.

With respect to the principles of justice and universalization, a similar consideration applies. Understood as mandates of optimalization, they still retain a regulative and substantive character that cannot be reformulated in the form of instrumental rules for a critical discussion.

In the case of Rawls's notions of rationality and reasonableness, remember that both notions concern the participants' attitudes (their individual capacity to abide by fair cooperation, and to revise their own view of a valuable human life). To that extent, these notions do not seem to concern as much the pragma-dialectical procedural rules as, maybe, what Pragma-dialectics has termed 'second-order' conditions. These conditions are related to the discussants' states of mind and attitudes, as for example that they are prepared to express their opinions and to listen to the opinions of others (van Eemeren and Grootendorst 2004: 189, 191). Yet it is undeniable that Rawls's notions go beyond the pragma-dialectical conditions, since they have a substantive character that the latter do not. For this reason, my conclusion is that Rawls's notions of rationality and reasonableness cannot be seen as close to the Pragma-dialectics ones.

Kock (2007) highlights a further dissimilarity. In contradistinction to both Rawls's and Habermas's views, Pragma-dialectics does not take the domains of episteme (empirical and factual) and praxis (ethical-political) to be different from an argumentative point of view. The same set of procedural rules can and should be applied within both domains, given that this set is apt to be agreed upon by the discussants. Against this tenet, Kock elaborates on Rawls's (1993) idea that, in the practical domain, 'the burden of reasons' or 'the burden of judgement' can lead to enduring disagreement. Kock says, "In the domain of praxis, enduring dissensus is inevitable and legitimate in a way that it is not in the epistemic domain" (2007: 182). According to him, a preeminent source of disagreement is what he terms the multidimensionality of practical argumentation, namely, the conflict of values that may arise as a result of an individual or group commitment to a plurality of values. This value conflict may have no intersubjective solution and lead to a "legitimate enduring dissensus" (2007: 187). Notwithstanding this, the author puts forward a set of rules drawn from the very notion of practical argumentation and some associated principles. Among these rules, the first one states that, for any point where dissensus exists, debaters must give reasons. Here, the golden rule of argumentation can be 
identified, as equally recognized in the different frameworks we have been considering.

Kock notices that his conclusion is at odds with Habermas's concept of a final consensus as the goal of practical dialogues, as well as with the Pragma-dialectics tenet that resolving a difference of opinion is the goal of argumentation. However, he takes his views to be in tune with Rawls's pluralism. Yet I think some doubts may arise concerning a hasty agreement on this point. As already said, for Rawls, the principles of justice are definite, in the sense that they define the very concept of justice. These principles are what rational and reasonable human beings would agree upon, under the conditions of the original position. Even if, under the guidance of the principles, the results of practical-political deliberations can be plural and divergent, the principles of justice themselves are not subjected to such pluralism. An enduring dissensus on the principles that should be adopted as principles of justice would lead to the dissolution of the very notion of just norms. In this sense, I conclude that the idea of legitimate enduring dissensus cannot be reconciled with a procedural, deliberative concept of the justice of norms.

\section{Conclusion}

My aim has been to clarify the role that certain practical norms play in practical argumentation, in particular in deliberations in which the justice of a claim is at stake. For that, I have introduced the framework of discursive theories of justice. After a presentation of the main guiding ideas and general principles in them, I have suggested that a distinction has to be made concerning the contribution of the principles of justice (Rawls) and universalization (Habermas). On the factual level of real deliberations, they play the role of a mandate of optimalization in deliberation processes dealing with the justice of norms. On the normative level of a categorical introduction of the very notion of justice, the principles can consistently be seen as definite mandates, even if this conceptualization is not entailed by their regulative use.

\section{N O T E S}

\footnotetext{
1 Notwithstanding this, a previous theoretical move worth noticing is that these theories narrow their scope by identifying moral rightness with justice, thus endorsing a notion of justice (and a fortiori of moral rightness) that is political and procedural. Thus, Habermas writes, "Justice questions concern the claims contested in interpersonal conflicts (...) Just
} 


\section{Cristina Corredor}

as 'true' is a predicate for the validity of assertoric sentences, so is "just' a predicate for the validity of the universal normative sentences that express general moral norms." (Habermas 1996: 153). And Rawls characterizes his own version of constructivism by writing, "Kantian constructivism holds that moral objectivity is to be understood in terms of a suitably constructed social point of view that all can accept. Apart from the procedure of constructing the principles of justice, there are no moral facts." (Rawls 1980: 519).

2 There is an additional idea in Rawls's views that concerns a conception of the person. He says, "Now, as I have said, a Kantian doctrine joins the content of justice with a certain conception of the person; and this conception regards persons as both free and equal, as capable of acting both reasonably and rationally, and therefore as capable of taking part in social cooperation among persons so conceived." (Ibid. supra: 518) This conception is closely related to Kant's Humanity formulation of the categorical imperative.

3 Cf. Habermas 1984, Chapter III, Intermediate reflections: social action, purposive activity, and communication.

4 See Bermejo-Luque 2011, whose interpretation of Toulmin's notion of warrant I am following here; cf. also Toulmin 1958: 91.

${ }^{5}$ Cf. Alexy 1988: 48, n. 12, where this author analyzes the conceptual difference between legal principles and legal rules.

${ }^{6}$ A similar distinction is introduced by Garcia-Carpintero (2011) by means of his differenciation between a weak (constitutive) and a strong (action-guiding) normativity in speech acts.

\section{R E F E R E N C E S}

Alexy, R. (1978). Theorie der Juristischen Argumentation. Frankfurt a.M.: Suhrkamp.

Alexy, R. (1988). Problems of Discourse Theory. Crítica 20(58), 43-65.

Alexy, R. (1993). Derecho y Razón Práctica. México: Fontamara.

Bermejo-Luque, L. (2011). Giving Reasons: A Linguistic-Pragmatic Approach to Argumentation Theory. Dordrecht: Springer.

Dancy, J. (2004). Ethics without Principles. Oxford: Clarendon Press.

van Eemeren, F. and Grootendorst, R. (1982). The speech acts of arguing and convincing in externalized discussions. Journal of Pragmatics 6, 1-24.

van Eemeren, F. and Grootendorst, R. (2004). A Systematic Theory of Argumentation: The Pragma-Dialectics Approach. Cambridge: Cambridge University Press.

Garcia-Carpintero, M. (2011). Constitutive vs. normative accounts of speech and mental acts. In A. Reboul (Ed.), Philosophical Papers Dedicated to Kevin Mulligan. URL http://www.unige.ch/lettres/philo/mulligan/festschrift/Gar cia-Carpintero-paper.pdf (Last accessed, 30 April 2018)

Gauker, C. (1997). Domain of Discourse. Mind 106, 1-32.

Habermas, J. (1984). The Theory of Communicative Action. Vol. I: Reason and the Rationalization of Society, T. McCarthy (trans.). Boston: Beacon. [German, 1981] 
Norms in Deliberation: The Role of the Principles of Justice and...

Habermas, J. (1990). Moral Consciousness and Communicative Action. C. Lenhardt and S. W. Nicholsen (Trans.). Cambridge, Mass.: The MIT Press. [German, 1983]

Habermas, J. (1996). Between Facts and Norms: Contributions to a Discourse Theory of Law and Democracy. W. Rehg (Trans.). Cambridge, Mass.: The MIT Press. [German, 1992]

Kock, C. (2007). Norms of legitimate dissensus. Informal Logic 27, 179-196.

Lafont, C. (2004). Moral objectivity and reasonable agreement: can realism be reconciled with Kantian constructivism? Ratio Juris 17(1), 27-51.

Mason, A. (2009). Justice, Holism and Principles. Res Publica 15, 179-194.

Rawls, J. (1999). A Theory of Justice. Cambridge, Mass.: The Belknap Press of Harvard University Press. [First Edition, 1971]

Rawls, J. (1980). Kantian Constructivism in Moral Philosophy. The Journal of Philosophy 77(9), 515-572.

Rawls, J. (1993). Political Liberalism. New York: Columbia University Press.

Rawls, J. (2001). Justice as Fairness: A Restatement. E. Kelly (Ed.) Cambridge, Mass.: Harvard University Press.

Sbisà, M. (2017). Varieties of Norms. In M. Witek and I. Witczak-Plisiecka (Eds.), Normativity and Variety of Speech Actions, to appear. Leiden: Brill.

Toulmin, S. (1958). The Uses of Argument. Cambridge: Cambridge University Press. [Updated Edition, 2003] 